\title{
Management of Supply Chain: X-to-order Concepts vs Make-to-stock Model
}

\author{
Mihiotis A. ${ }^{1}$ \\ ${ }^{1}$ School of Social Sciences, Hellenic Open University, Patras, Greece \\ Correspondence: Mihiotis A., School of Social Sciences, Hellenic Open University, 57-59 Bouboulinas Str., 26222 \\ Patras, Greece. E-mail: mihiotis@eap.gr \\ Received: February 23, 2014 \\ Accepted: March 19, 2014 \\ Online Published: April 30, 2014 \\ doi:10.5430/ijba.v5n3p30 \\ URL: http://dx.doi.org/10.5430/ijba.v5n3p30
}

\begin{abstract}
In a challenging market, companies' ability to act faster is considered a basic advantage. From a value chain aspect, when a company cannot change its internal production processes and the external supply streams according to the demand requirements, this may lead to sales reduction or stock left-overs. $X$-to-order concepts [where $\mathrm{X}=\mathrm{A}$ (ssemble), $\mathrm{M}(\mathrm{ake}) / \mathrm{B}$ (uilt) and $\mathrm{E}$ (ngineer)], are key types of supply chain planning, where the production process starts after the orders are placed. Those methods have caught the attention of both researchers and businesses because of the advantages they offer in business procedures and the customization of consumers needs. The aim of this paper is to present the framework of supply chain management of the $X$-to-order concepts in comparison to the make-to-stock model and depict the main differences between these two approaches.
\end{abstract}

Keywords: supply chain management, assemble-to-order, make-to-order, built-to-order, engineer-to-order, make-to-stock, X-to-order

\section{Introduction}

Different customer needs and preferences as well as technology's rapid development characterize today's market environment (Hsu and Wang, 2004). These factors have resulted in the development of different products and helped production managers to develop supply chains in order to address hesitations raised from inconsistency in demand (Gunasekaran and Ngai, 2009).

In a challenging market, companies' ability to act faster is considered a basic advantage. From a value chain aspect, the most important thing is the partners' correspondence speed: when a company cannot change its internal production processes and the external supply streams according to the demand requirements, this may lead to sales reduction or stock left-overs (Engelhardt-Nowitzki, 2012).

Nowadays, the global markets' competitive environment is mainly characterized by the wide variety of consumers' needs for products and services. Flexibility and responsiveness to customer needs become critical strategic issues regarding business production systems, aiming at the increase their market share. The global market changes have forced many multinational companies to redefine their production strategy. The traditional centralized production processes tend to become more decentralized in order to expand into new markets. To achieve this, companies are modifying their production strategies and tactics in order to meet the markets' needs (Gunasekaran and Ngai, 2005). Businesses are operating in a context of a broader supply chain (Demirli and Yimer, 2008) and their success tends to be influenced by the formulation of strategic alliances with other companies in order to ensure the effective flow of products to the final consumers (Reev and Srinivasan, 2005).

In order to achieve the above goals, there is a need for an efficient supply chain that could convert processes from mass production to mass customization. The idea of mass customization entails the ability to use flexible processes and organizational structures to produce varied and customized products and services at the same price as mass produced products are delivered (Hart, 1996). Mass customization has become a strategic goal for many companies who have developed X-to-order concepts to meet customer needs (Gunasekaran and Ngai, 2005). According to Yang and Burns (2003), X-to-order strategies can be classified in the following three basic concepts:

- ETO (Engineer-to-order)

- MTO / BTO (Make-to-order) / (Built-to-order)

- ATO (Assemble to order) 
The above strategies define supply chain's concept, dealing with customer needs. This comes to contradiction to the push type supply chains strategy, where the products are developed and delivered based on the predicted orders, without taking under account the specific consumer needs. Furthermore, when adopting the X-to-order strategy, enterprises gain the ability to customize their products efficiently to such an extent that they are able to satisfy specific customer requirements, while reducing, at the same time, the overall costs (Demirli and Yimer, 2008).

In the second section of the study the main alternative types of supply chain planning are presented. The third section deals with the advantages of X-to-order concepts and the conditions for their implementation. The fourth and last section compares the two approaches of supply chain management, depicts the main differences and offers conclusions.

\section{Basic Types of Supply Chain Planning}

The various manufacturing conditions depend on production ability to handle customization processes or to develop a wide range of products. According to Olhager (2003), the order penetration point (OPP) defines the stage in the manufacturing value chain, where a particular product is linked to a specific customer order. This is why according to Van Donk (2001) it is a very important concept in the design and management of the manufacturing value chain. It distinguishes forecast-based production from the order-based production. This procedure facilitates companies to acquire data and manage the production flow. Based on forecasting methods, it is less sensitive on market irregularities, facilitating the upstream activities.

The following figure (Olhager, 2003), shows the relation between the product delivery strategies (Make-to-stock, Assemble-to-order, Make-to-order, Engineering-to-order) and different OPP levels. Dotted lines depict the forecast-based production whereas the straight lines depict the order-based production activities.

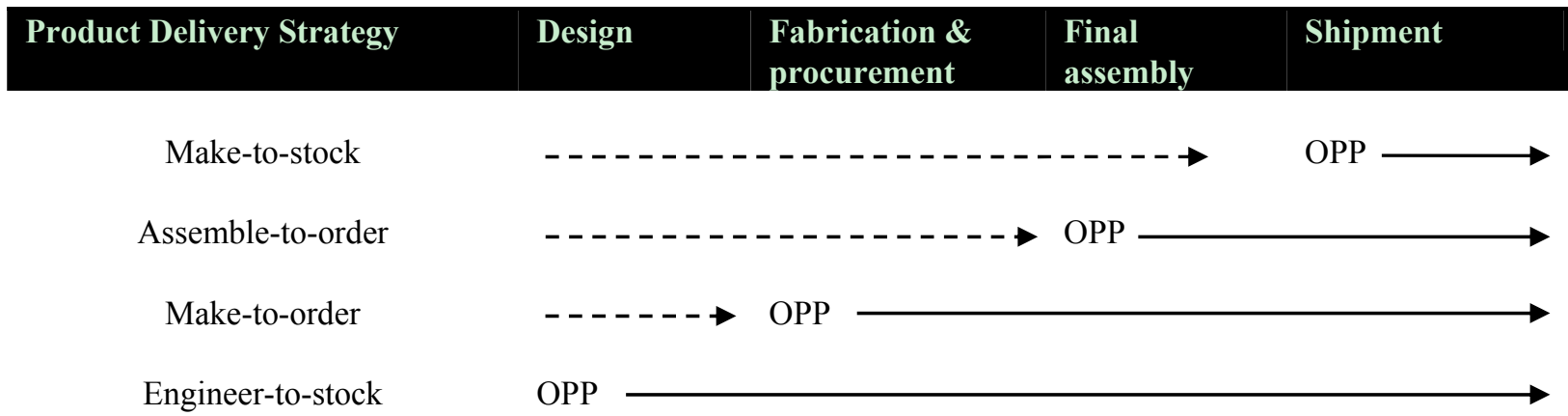

Figure 1. Different product delivery strategies relate to different OPPs

Source: Olhager, 2003

Olhager (2003) talks about the factors that affect the positioning of the order penetration point and he divides them into three groups: (a) Market related factors, including delivery lead-time requirements, product characteristics like volume and range and customer preferences like order size and order frequency, (b) Product related factors, including modularity characteristics, customization opportunities and product structure and (c) Production related factors, including production lead time and process flexibility.

\subsection{Make-to-stock (MTS)}

In the MTS model the company develops and stores goods at the warehouse to a certain predefined point without taking under account the customer preferences. In such a system, the person in charge, inspects the inventory in and submit orders according to the warehouses ability to accommodate products, so that the capacity utilization of the warehouse remains in a high level. Only few companies nowadays operate by this way, due to the fact that this method may lead to obsolete stock because if the demand falls then the stock will remain on the warehouse. MTS inventory model would be acceptable only where the following conditions would be present: (i) When product demand is absolutely stable and foreseeable, (ii) Small number of product lines, (iii) Transition times between products are extensive and inventories are expensive. Through this model, products are produced at the beginning and the supply chain is characterized by a faster response time to the customer. This model is applied in daily use of low-value products, such as detergents etc., and cover customers' needs for an immediate response in daily use products. Yet, there is no option for product customization and therefore the MTS model is characterized by a lack of flexibility in the variety offered to the consumer (Blanco, 2002).

\subsection{Engineer-to-order (ETO)}

ETO is a production process in which the specifications of the developed products are based on the orders submitted. In such a concept, customers' specific needs may result to different fit, form and function of the final product. This is 
referred to a single or a small amount of products that is why ETO has nothing to do with "mass customization". In this model, the process starts with the product design. The procedure offers a high degree of customization and requires unique designs as part of the construction. These products are made for specific purposes and their production process is very expensive (Gosling and Naim, 2009). Due to the customized nature of the products, the products are created from the beginning of the project procedures and the production process characterized as time consuming.

\subsection{Make-to-order (MTO) / Built-to-order (BTO)}

Basically, a MTO system is a Just in time production system which aims to operate on the principles of lean production. This means that consumer defines when and what products will be produced. Production begins when customer's order is received and confirmed. This could be achieved through an inventory/production management program or manually. In this concept the consumer demands are shared across all the supply chain, achieving by this way balanced and more effective production. A lot of companies function with this model and the benefits are: (i) Reduced production waste, (ii) Less work in progress, (iii) Reduced inventory holding costs, (iv) Better customer lead times and flexibility to adjust to consumer demand changes, (v) Improved cash flow. As soon as an order is placed, production line starts to produce exact quantities following predetermined time constraints. The lead time is longer in MTO than in BTO.

\subsection{Assemble-to-order (ATO)}

ATO describes a production process in which goods or services can be gathered after receipt of a customer's order. The basic parts of a product are developed and stocked waiting for a customer order. As soon as the order comes, the customized products assembly begins. This concept is used when a variety of products can be assembled from a pool of basic parts.

\section{X-to-order Concepts (XTO, where $\mathrm{X}=\mathrm{E}, \mathrm{M} / \mathrm{B}, \mathrm{A})$}

The XTO concept is focused to facilitate all parts of the supply chain gain a competitive advantage that will reflect to the products success. XTO applies to all the members of the supply chain and it is quite usual a members interest to differ from another. That is why XTO management should make decisions to compromise possible conflicts; e.g. suppliers may ask for smooth delivery rates while logistics may ask for high fleet utilization. XTO is very important due to the increasing global competition since multinational companies are trying to secure market share and improved profits by utilizing global supply chains (Gunasekaran and Ngai, 2009).

The X-to-order concept is based on the following strategy: a value chain that produces quality products or services which are based on the requirements of a customer or group of customers and are offered at competitive prices within a short period of time by leveraging core competencies of corporate allies or suppliers that will provide necessary parts and support services.

The main objectives of the X-to-order concept are the following:

- The determination of the ideal product mix based on products demand.

- The determination of the idea point of product diversification in the value chain.

- The optimization of logistics costs.

- The response to the individual clients needs in a short delivery time

- The reduction of inventory and production costs along the value chain.

The main purpose of a supply chain management based on the X-to-order concept is the maximization of customers' satisfaction by providing personalized products on time. X-to-order meets customers' needs through adjustments to their particular specifications. The customization procedure varies depending on the type of product; therefore, when a company opts for a strategy of X-to-order, there should be a close relationship with suppliers, distributors and other partners at hand.

The XTO concept is a supply chain management approach, which begins from the stated demand and after a confirmed order from a customer. According to this approach the ordering submission system receives information from the provisioning and ordering system and then, directs the supplier chain to the production of the ordered product (Parry and Graves, 2008; Gunasekaran and Ngai, 2005). For an effective application of the XTO concepts, companies should invest capital in order to reorganize their organizational structure and to develop new technical operations. The traditional distribution channels should be reformed into innovative complex systems.

Allowing products to be distributed according to customers' needs, companies should also invest in human capital with the retraining of the existing staff and the recruiting of new specialized staff. Additionally, the successful XTO model operation demands not only for the manufacturer to be flexible in production but the suppliers as well should comply with the standards set in order to respond efficiently to customers' orders. For that purpose companies should 
generate strategic alliances at core competencies with the use of integrated information systems (Holweg and Pil, 2001).

\section{Conclusions}

The XTO model differs from the traditional supply chain management (MTS) not only in its fundamental business activities like marketing, production and logistics but in a variety of procedural activities such as customer relationships, uncertainty management, inventory policy of final products and the establishment of intergrated procedures with the supplier.

In the traditional supply chain management, customer requirements are covered from the inventory since there is a fixed production plan based on the expected demand. The uncertainty factor is reduced by the stock maintenance of finished products and the procedures can be characterized as intermediate-oriented rather than customer-oriented.

In contrary, in the XTO model the production is based on customer orders, the supply chain is characterized by flexibility and the procedures are strongly customer-oriented. The availability of product particles and sub-products is the factor that diminishes the uncertainty environment and not the inventory of the finished products. Moreover, the XTO model is characterized by a quick response time in delivery in contradiction to the traditional supply chain.

Another important difference concerns the level of flexibility and responsiveness to the ever changing environmental conditions. The traditional "push type" model depends on the establishment of long-standing relationships with the intermediates. On the other hand, XTO is a "drawn type" model, as the materials are drawn through the supply chain and according to customer orders. In such an environment, the processes are well structured and running according to consumers needs. In every differentiation of customers' preferences, the product mix changes immediately to cover the new demand. So, the XTO concepts allow manufacturers to respond more effectively to market conditions. The marketing activity in these cases has an important role because firms are required to maintain the optimum "working relationship" with customers to ensure customer satisfaction through a constant supply of quality products.

\section{References}

Blanco, A. (2002, Oct.). Build to stock program delivers machines in hurry. Plastics Engineering, Brookfield Center, $58(10), 23$.

Christensen, W.J., Germain, R., \& Birou, L. (2005). Build-to-order and just-in-time as predictors of applied supply chain knowledge and market performance. Journal of Operations Management, 23, 470-481. http://dx.doi.org/10.1016/j.jom.2004.10.007

Demirli, K., \& Yimer, A. (2008, July). Fuzzy scheduling of a build-to-order supply chain. International Journey of Production Research, 46(15), 3931-3958. http://dx.doi.org/10.1080/00207540601113273

Engelhardt-Nowitzki, C. (2012). Improving value chain flexibility and adaptability in build-to-order environments. International Journal of Physical Distribution and Logistics Management, 42(4), 318-337. http://dx.doi.org/10.1108/09600031211231317

Gunasekaran, A., \& Ngai, E.W.T. (2005). Build-to-Order Supply Chain Management: A literature review and framework for development. Journal of Operations Management, 23(5), 423-451. http://dx.doi.org/10.1016/j.jom.2004.10.005

Gunasekaran, A., \& Ngai, E.W.T. (2009). Modeling and analysis of build-to-order supply chains. European Journal of Operational Research, 195(2), 319-334. http://dx.doi.org/10.1016/j.ejor.2008.03.026

Hart, C. (1996). Made to order, Marketing Management, 5(2), 10-23.

Holweg, M., \& Pil, F. (2001). Successful build-to-order strategies: start with the customer. Sloan Management Review, 43(1), 74-83.

Olhager J. (2003). Strategic positioning of the order penetration point. International Journal of Production Economics, 85(3), 319-329. http://dx.doi.org/10.1016/S0925-5273(03)00119-1

Parry, G., \& Graves, A. (2008). Build To Order: The Road to the 5-Day Car. Springer-Verlag London Limited. http://dx.doi.org/10.1007/978-1-84800-225-8

Reev, J. M., \& Srinivasan, M. M. (2005, May /June). Which supply chain design is right for you?, Supply chain management Review, 9(4), 50.

Van Donk, D.P. (2001). Make to stock or make to order: The decoupling point in the food processing industries. International Journal of Production $\quad$ Economics, $\quad 69(3), \quad 297-306$. http://dx.doi.org/10.1016/S0925-5273(00)00035-9 